\title{
Effectiveness, structure, and content of nurse counseling in gynecologic oncology: a systematic review
}

\author{
Silvia Raphaelis ${ }^{1 *} \mathbb{D}$, Andrea Kobleder ${ }^{2}$, Hanna Mayer ${ }^{1}$ and Beate Senn $n^{2,3}$
}

\begin{abstract}
Background: Gynecological pre-cancer and gynecological cancers are considerable diseases in women throughout the world. The disease and treatment lead to numerous biopsychosocial issues. To improve the outcomes of affected women, several counseling interventions have been tested thus far in nursing research. These interventions target different endpoints and are composed of various structural and content components. The purpose of this research was to systematically review the effectiveness of nurse counseling on any patient outcomes tested so far in gynecologic oncology before, during and after treatment and to explore structure and content components.

Methods: Experimental, quasi-experimental, and pre-experimental studies assessing the effectiveness of nurse counseling in women with gynecological neoplasia were searched for in PubMed ${ }^{\oplus}, \mathrm{CINAHL}^{\oplus}, \mathrm{PsychINFO}^{\circledast}$, Cochrane ${ }^{\oplus}$, and EMBASE ${ }^{\circledast}$. Reference lists were hand-searched and relevant authors were contacted. Moreover, the evidence level and methodological quality of the included studies were assessed. Afterwards, the effect of nurse counseling on each identified patient outcome was narratively analyzed. To identify the structural and content components of the included interventions, a structured content analysis was performed. Finally, it was determined which components were associated with favorable outcomes within the included studies.
\end{abstract}

Results: Seven experimental and three pre-experimental studies, reporting the effects of 11 interventions on a total of 588 participants, were eligible. No study investigated women with pre-cancer. Three studies had a high, five a moderate, and two a low methodological quality. Positive effects were found on quality of life, symptoms, and healthcare utilization. Eight structural components and four content components composed of various sub-components were identified and linked to specific effects.

Conclusions: The current evidence base is fragmented and inconsistent. More well-designed, large-scale studies including women with pre-cancer are warranted. Most convincing evidence indicates that nurse counseling can improve symptom distress. Components associated with the most trustworthy effects include nurses with an academic education; repeated and individual consultations during and after active treatment; structured, tailored, interdisciplinary orientated, and theoretically based counseling concepts; specific materials; comprehensive symptom management; and utilization of healthcare services. Healthcare providers and researchers can use the findings of this review for the systematic development of nurse counseling in gynecologic oncology.

Keywords: Systematic review, Oncology nursing, Female genital Neoplasms, Counseling, Patient education as topic

\footnotetext{
*Correspondence: silvia.mona.raphaelis@univie.ac.at

${ }^{1}$ Department of Nursing Science, University of Vienna, Alser Strasse 23, 1080

Vienna, Austria

Full list of author information is available at the end of the article
} 


\section{Background}

Women with gynecological neoplasia are affected by cellular changes in the female reproductive organs, such as the uterus, ovaries, cervix, vulva, and vagina. These cellular changes can be based on precancerous (e.g., cervical intraepithelial neoplasia) or cancerous (e.g., cervical cancer) neoplasia. They represent considerable diseases in women all over the world with an annual incidence of 1 to $2 \%$ for gynecological pre-cancer [1-3] and of 14.5 to $22.1 \%$ for gynecological cancer [4]. Especially if left untreated, some pre-cancers may develop into invasive cancer $[5,6]$. Due to this linkage, some precancerous conditions (e.g., vulvar intraepithelial neoplasia grade III) are incorporated as carcinoma in situ $[7,8]$ in the international classification of specific gynecologic cancer forms. Pre-cancers are usually detected by abnormal clinical, cytological (e.g., Papanicolaou's test), or human papillomavirus findings which require further examination by colposcopy and/or biopsy to gain a certain diagnosis $[9,10]$. For gynecological cancer, various diagnostic procedures, from imaging techniques to histological examinations, are available. After diagnostic clarification, appropriate medical treatment (e.g., surgery) and care $[3,10,11]$ is scheduled for women of both conditions, within the same cancer-specialized healthcare settings and performed by the same oncological healthcare providers [12-14]. The disease and treatment leads to similar biopsychosocial symptoms for women of both conditions [15], including pain, fatigue, and anxiety affecting quality of life $[12,13]$ and issues of women's health, such as femininity, sexuality, and intimate relationships [16-18]. Qualitative studies, in particular, indicate that affected women need specific counseling regarding their concerns [19-22].

Several studies have so far evaluated the effect of nurse counseling in women with gynecological neoplasia. The study interventions are comprised of various structural and content components that cover a broad range in terms of the intervention provider, the time frame, the mode of delivery, and the content provided. Studies concerning pre-cancer have primarily investigated women who were scheduled for colposcopy to further diagnose preliminary findings (e.g., [23]). In women with gynecologic cancer, several intervention studies (e.g., [24-26]) and the systematic review by Cook et al. [27] are available. However, the systematic review focuses solely on the impact of specialized nurses on selected outcomes (quality of life, patient satisfaction, psychological outcomes) and in a brief section on specific structural components (time frame, mode of delivery).

Thus, the effectiveness of nurse counseling on different patient outcomes in women with gynecological neoplasia, as well as the structural and content components of these counseling interventions, have not been comprehensively reviewed to date. To inform future research and healthcare providers about the current evidence base in this area, this review aims to:

(1) explore the impact of nurse counseling on different patient outcomes,

(2)identify structure and content components of interventions tested so far, and

(3) determine which components are associated with favorable outcomes.

\section{Methods}

\section{Search and screening strategy}

A comprehensive literature search $[28,29]$ was performed in PubMed $^{\oplus}, \mathrm{CINAHL}^{\oplus}$, PsychINFO ${ }^{\circ}$, Cochrane $^{\oplus}$, and EMBASE $^{\oplus}$ until July 2016. The search strategy (Fig. 1) was developed for PubMed and then adapted for all other databases. To identify additional studies, reference lists of relevant articles were hand-searched and authors contacted.

Inclusion criteria for retrieved records were English publications of experimental (randomized controlled trials), quasi-experimental (pretest-posttest studies and time series with non-equivalent comparison groups), or pre-experimental (one-group pretest-posttest studies and posttest-only studies with comparison groups) studies assessing the effectiveness of nurse counseling. Nurse counseling was defined as a problem-solving approach to support patients by a voluntary, interaction-intensive orientation, planning, and decision process. All outcomes of women with gynecological pre-cancer confirmed by colposcopy/biopsy (cervical, vulvar, or vaginal intraepithelial neoplasia) or with gynecological cancer (of the cervix, vulva, vagina, endometrium, ovary, or fallopian tube) were eligible. Interventions not mainly provided by a nurse and those designed for palliative patients, children, or adolescents were excluded.

\section{Study selection}

After removing duplicates, two authors (SR and AK) independently screened the titles and abstracts of all records and, subsequently, the full-text versions of all remaining records for eligibility. They documented the inclusion and exclusion criteria for each study and discussed disagreements until consensus was reached.

\section{Assessment of study quality}

Subsequently, the two authors independently assessed the methodological quality of included studies, whereby a statistician supported the appraisal of appropriate statistical analysis. Experimental studies were assessed with the Joanna Briggs Institute 2014 [30] (JBI) tool for Randomized Control/Pseudo-randomized Trials and for all other studies, the JBI tool for Descriptive/Case Series Studies was appropriate (Additional file 1). The sum 


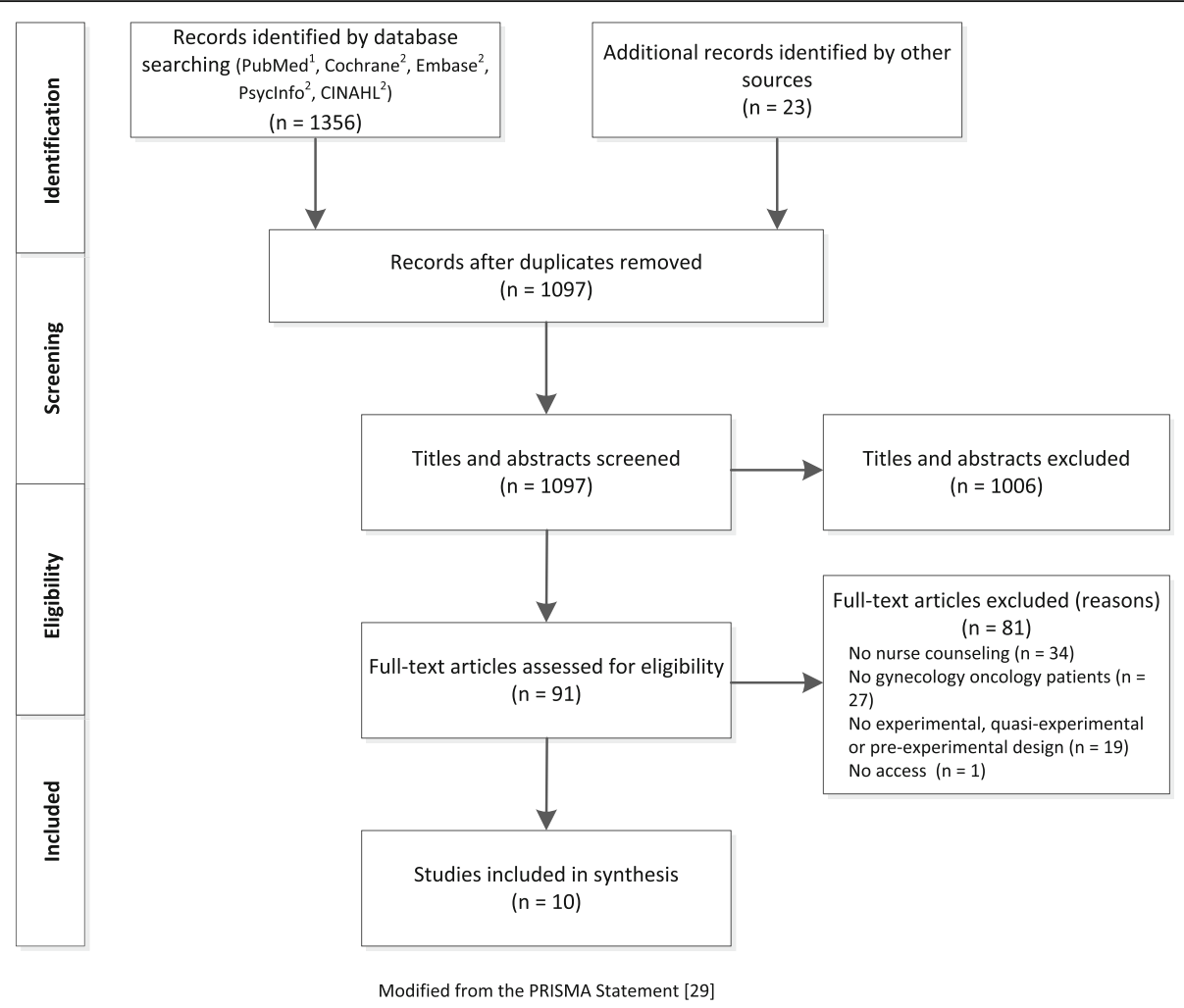

Fig. 1 Flowchart of study selection. ${ }^{1} P u b M e d: \# 1$ : randomized controlled trial[pt] OR controlled clinical trial[pt] OR randomized[tiab] OR randomly[tiab] OR clinical trials as topic[MeSH: noexp] OR trial[tiab] OR groups[tiab]; \#2: female genital neoplasms[MeSH]; \#3: gyn?ecologi* OR Female genital OR ovar* OR fallopian tube OR uter* OR corpus OR endometri* OR cervi* OR vagin* OR vulv*; \#4: cancer* OR carcinoma* OR sarcoma* OR malignan* OR neoplas* OR oncolog* OR tumor* OR tumour* OR adenocarcinoma* OR melanoma* OR dsyplas* OR papillomavirus infection [MeSH]: \#5: 3 AND 4; \#6: 2 OR 5; \#7: nursing[MeSH] OR nurses[MeSH] OR nurs*; \#8: counseling[MeSH] OR teaching materials[MeSH] OR patient education as topic[MeSH] OR self care[MeSH] OR education[MeSH] OR pamphlet[MeSH] OR [health promotion[MeSH] OR telephone[MeSH] OR counsel* OR "patient education" OR "self management" OR symptom management" OR "self care" OR inform* OR support* OR advice* OR consult* OR session* OR workshop* OR nurse management OR specialized OR specialized OR (psychosocial AND(intervention* OR support* OR program*)); \#9: 8 OR 9; \#10: 1 AND 6 AND 10. ${ }^{2}$ The PubMed search strategy (see above) was adjusted to the database interfaces of Cochrane, Ovid, and EBSCO

quality score for each study was converted into percentage values and interpreted in accordance with studies based on similar methodologies (e.g., [31, 32]). Values from 0 to $49 \%$ were defined as of low methodological quality, and those from 50 to $79 \%$ and from 80 to $100 \%$ as of moderate and high methodological quality, respectively. The two authors compared their assessment results against one another and discussed any disagreement until consensus was reached. Finally the evidence level (Additional file 2) of each included study design was determined with the JBI classification [33] (from level 1 , experimental designs, to level 4 , observationaldescriptive designs).

\section{Data extraction}

After this assessment process, the first author extracted the characteristics and results of all included studies and contacted the study authors to gather any missing information in this regard.

\section{Methods of synthesis}

For data synthesis, the effect of nurse counseling on each identified patient outcome was narratively analyzed regarding (1) direction of the effect, (2) consistency of the effect across studies, and (3) strength of the evidence for the effect (evidence level, study quality) in accordance with the systematic review methodology [28, 34]. To identify structural and content components, the study reports of included studies were analyzed with a structured content analysis [35, 36]. Identification of structural components was directed by the question of how nurse counseling was performed (who counseled whom, where, when, how often, how long, with what, and under which counseling concept?). In contrast, identification of content components was driven by the question of what themes were addressed during nurse counseling (what was counseled?).Throughout the process, the category system (main and sub-components of nurse counseling) was developed by a deductiveinductive strategy. Main components were developed by 
deduction from the above mentioned questions, whereas sub-components were formed by induction and deduction (by consultation of similar work (e.g., [27, 37, 38]) and literature-based conceptualizations (e.g., [39, 40]). Coding was performed at the level of paragraphs, phrases, and words by progressively summarizing the material. Data synthesis is presented by a description of the category system that emerged, the frequency of the components, and their association with effects on specific patient outcomes under consideration of the best available evidence (by evidence level and study quality).

\section{Results}

\section{Summary of included studies}

The literature search yielded 1356 records, from which ten studies could be included (Fig. 1). Seven investigations were experimental level 1 studies [25, 26, 41-45] and three were pre-experimental level 4 studies [46-48]. Three studies were of high $[25,43,44]$, five were of moderate $[26,42,45,47,48]$, and two were of low methodological quality $[41,46]$. The interrater-reliability of the two authors who assessed the methodological quality was substantial (Cohen's kappa $=0.84$ ). Experimental trials suffered mostly from blinding of participants and an appropriate intention-to-treat approach. Pre-experimental trials mostly lacked strategies concerning confounding factors and an appropriate intention-to-treat approach (Additional file 3). The samples of three studies were considered as small, with fewer than 30 participants per study group $[26,42,48]$ and therefore at risk for introducing type II errors. The studies by McCorkle et al. [43, 44] and by Donovan et al. [25] provide the best available evidence. Across all included studies, a total of 588 participants were investigated. Participants with various gynecological cancer sites were investigated most frequently $[26,41,42,45]$. However, none of the studies included women with pre-cancer confirmed by colposcopy/biopsy. Across all included studies, 11 interventions were tested in total: the two reports of McCorkle et al. [43] and [44] address the same intervention, and each of the studies by Liu et al. [48] and Nolte et al. [45] examined two interventions. Two studies $[45,48]$ compared different counseling interventions against each other, while all others compared counseling with usual care. Of the ten authors contacted, six provided additional information. Study and intervention characteristics, effectiveness results, evidence level (thereinafter referred to as experimental or pre-experimental study), and study quality are presented in Table 1.

\section{Effects of nurse counseling}

The effectiveness of nurse counseling is described in four main outcome groups: quality of life, symptoms, self-care performance, and healthcare utilization. The outcome group 'quality of life' refers to all reported effects of nurse counseling on quality of life total scores (such as overall quality of life) and quality of life sub-dimensions (such as cognitive or emotional quality of life dimensions) as measured and defined by the quality of life questionnaires used within the included studies. In distinction to the 'symptom' outcome group it is noteworthy that some quality of life measures used in the included studies contain questions about the occurrence of specific symptoms (e.g., [26]). For data synthesis it was not feasible to reconstruct which effects on symptoms were observed in these quality of life measures and to subsume them under the 'symptom' outcome group since studies did not report findings of single items. The outcome group 'symptoms' includes all reported effects of nurse counseling on physical and psychosocial symptoms outside quality of life measures as well as on the symptom severity, symptom distress, symptom consequences and symptom controllability of physical and psychosocial symptoms in general. In the outcome group 'self-care performance' only the performance of patients regarding physical symptoms was described in the included studies. Finally, the outcome group 'healthcare performance' refers to all reported effects of nurse counseling on the number of hospitalizations, oncology outpatient visits, emergency room visits, and primary care visits. The results are separated in each of these groups by experimental and pre-experimental studies.

\section{Quality of life}

In none of the experimental studies 'functional' [42], 'emotional' [26, 42], 'social' [26, 42], or 'sexual' [26] quality of life dimensions improved significantly with nurse counseling (Additional file 4). These results are based on moderate study quality [26, 42]. Contradictory results appeared in overall quality of life, as well as in the 'physical' and 'cognitive' aspects. Two studies with moderate quality observed significant positive effects on overall quality of life [26, 42], but not on the 'physical' and 'cognitive' dimensions. Conversely, the study by McCorkle et al. [43], with high methodological quality, reported no significant effects on overall quality of life, but did report effects on the 'physical' and 'cognitive' dimensions. Like all other studies, the pre-experimental study by Cox et al. [46], with low methodological quality, found no significant improvement of the 'social' and 'functional' aspects; similar to some of the other studies, it observed no effects on overall quality of life [43] and 'physical' aspects $[26,42]$, and, however, it was the only study that found significant improvements in 'emotional' quality of life dimensions.

\section{Symptoms}

Physical symptoms were measured in one pre-experimental study. The study was of moderate quality and compared 


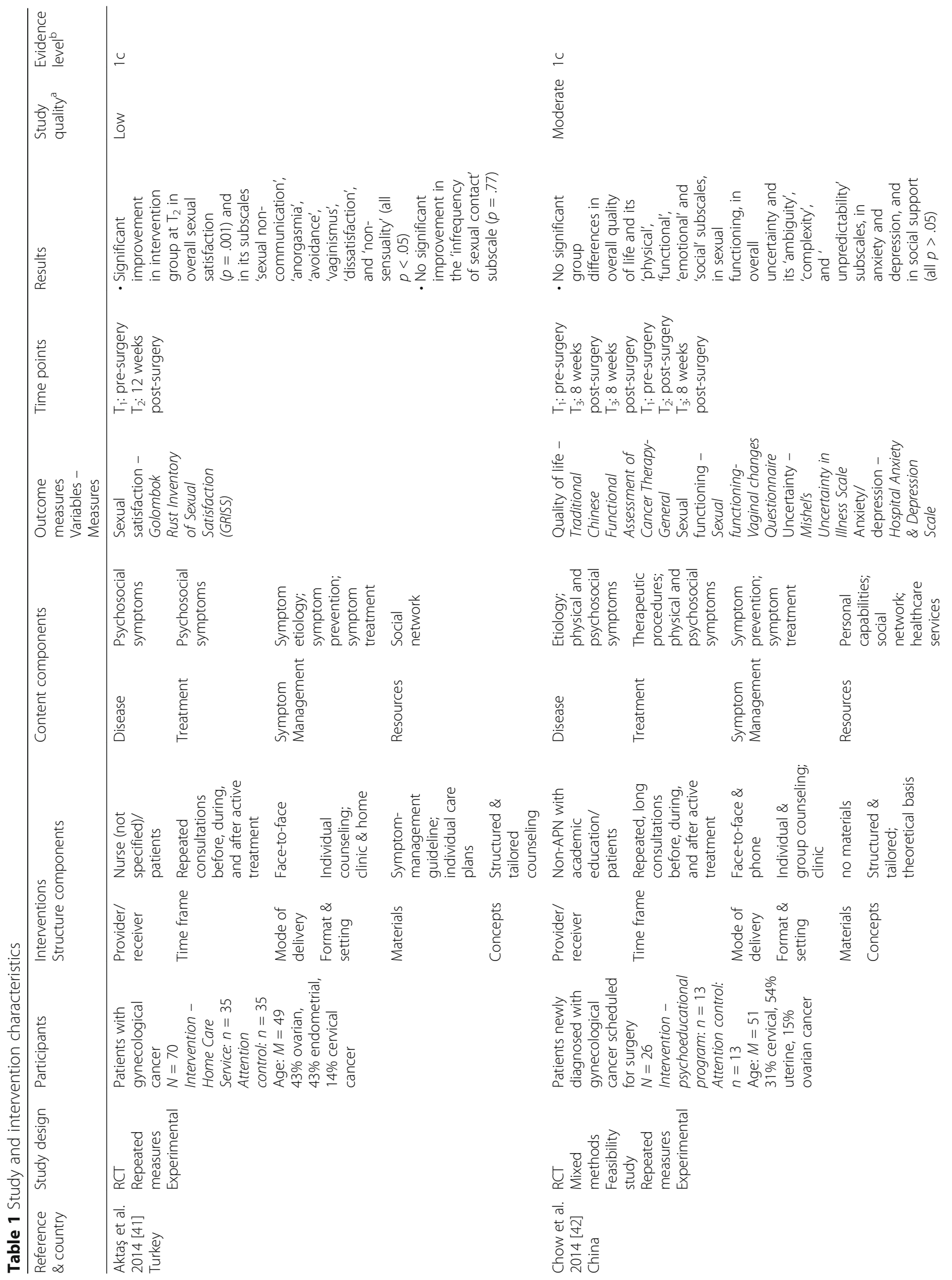




$\begin{array}{lll}y & \simeq \\ 3 & \frac{7}{3} & \frac{5}{1}\end{array}$

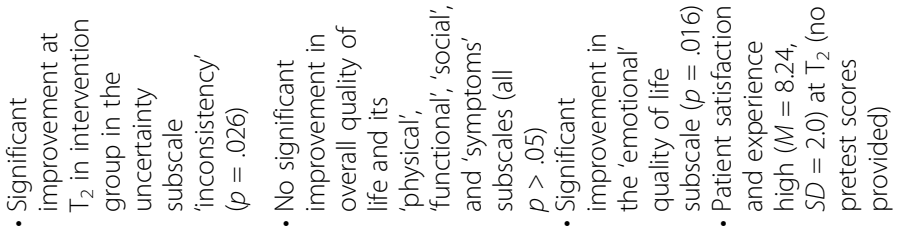

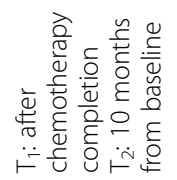

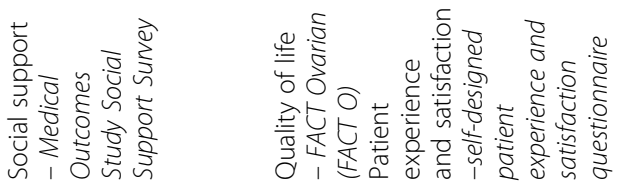

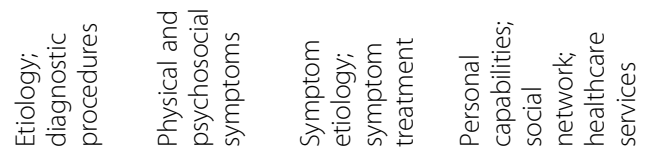

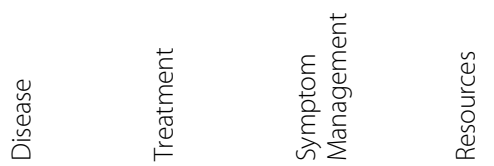

돞
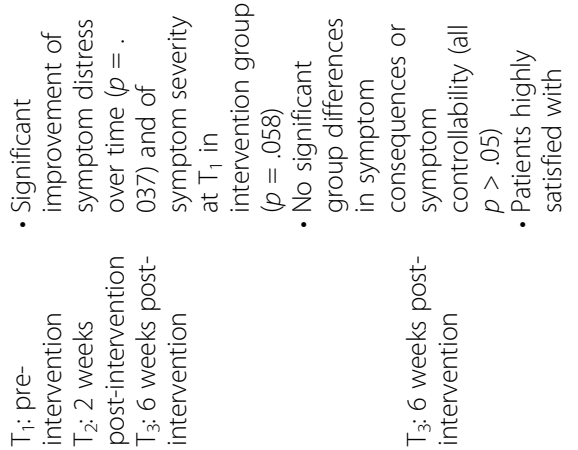

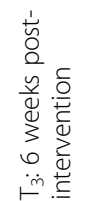

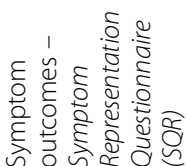

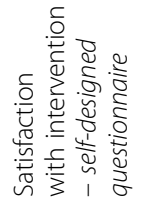

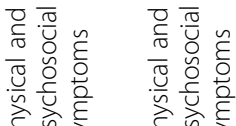

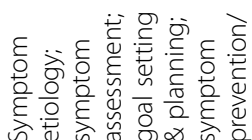

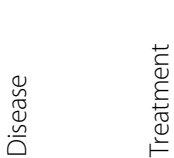<smiles>[13CH3][13CH3]</smiles>

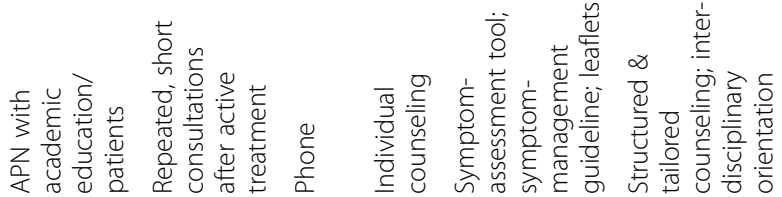

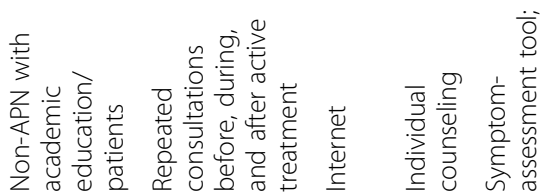

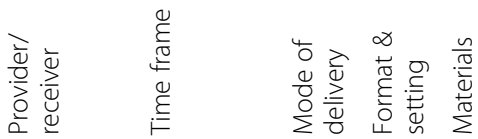

气ัँ

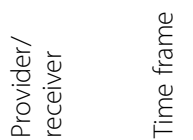

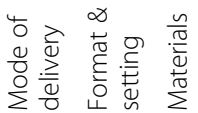

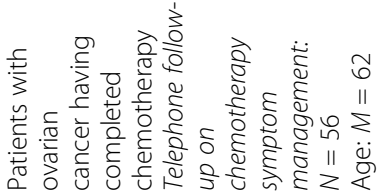

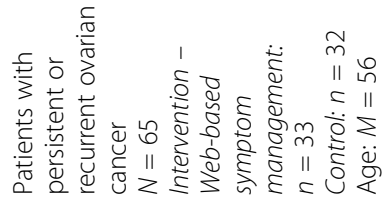

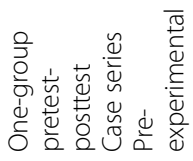

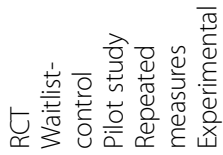

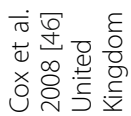

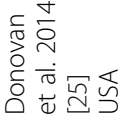


$\frac{8}{7}$
$\frac{8}{0}$
$\frac{0}{\frac{0}{0}}$
$\frac{0}{2}$

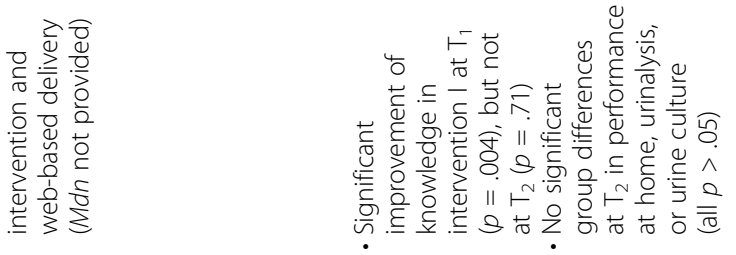
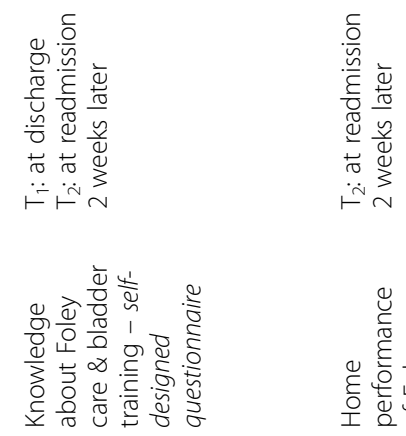

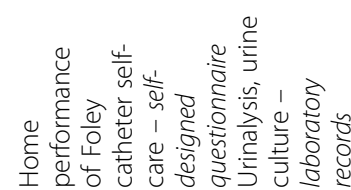

$\cup$
$\because$
$\frac{ \pm}{0}$
$\frac{0}{0}$
$\frac{0}{0}$
$\frac{0}{2}$
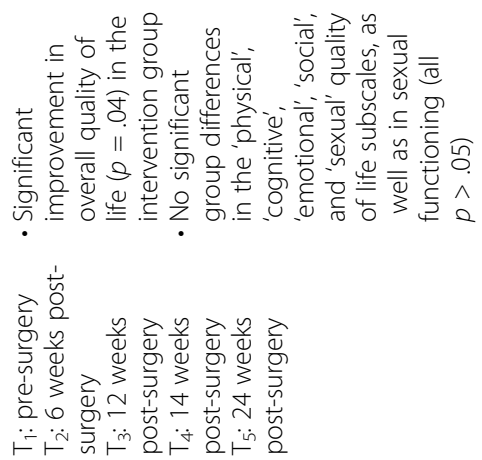

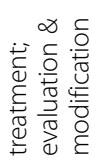

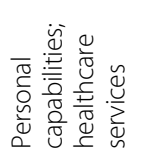

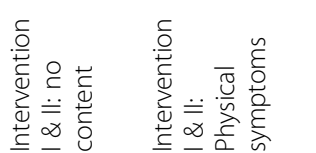

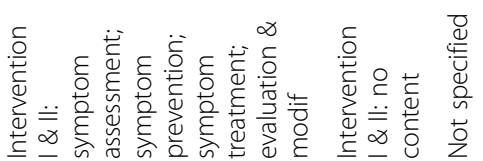

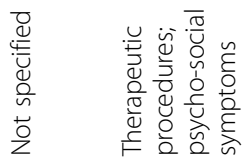

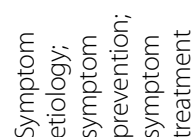

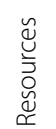

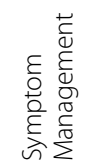

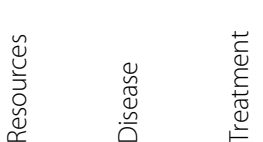

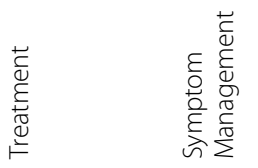

岕

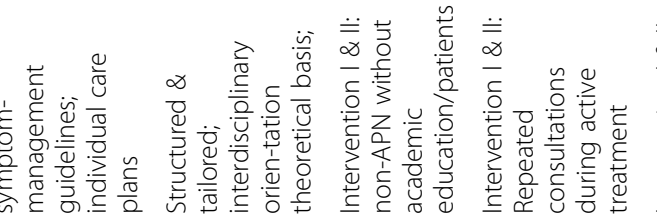

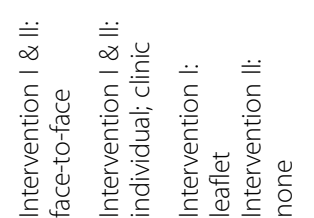

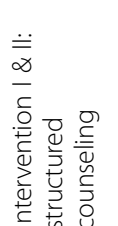

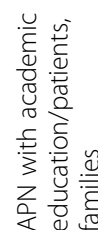

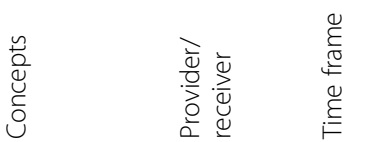

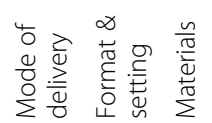

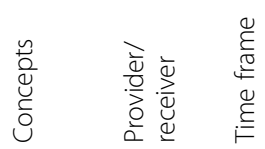

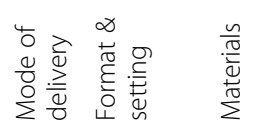

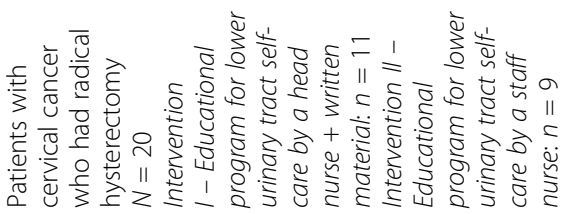

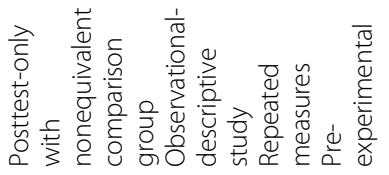

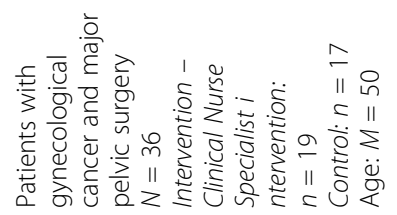

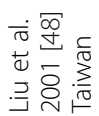

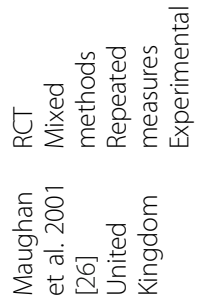


$\cup$

$\frac{\text { 을 }}{\frac{1}{1}}$

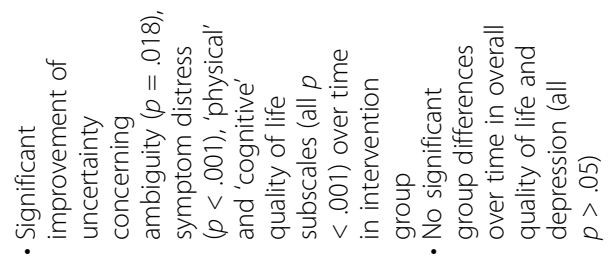

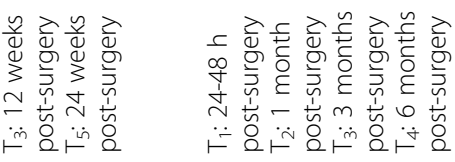

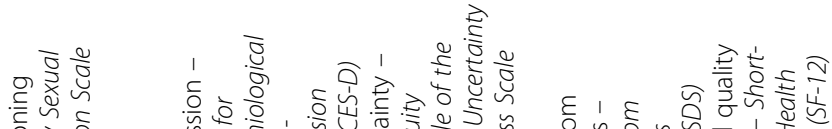

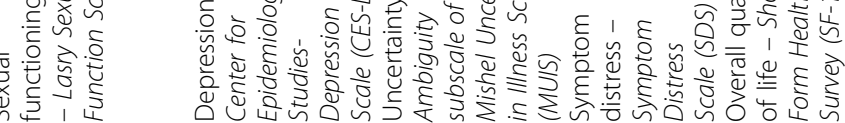

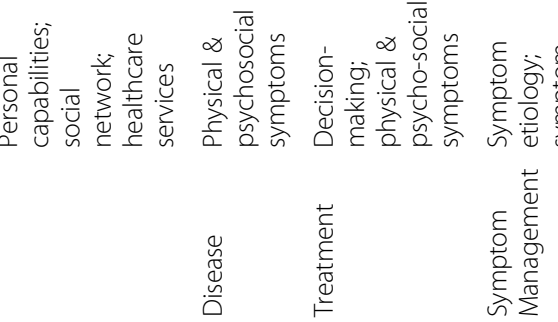

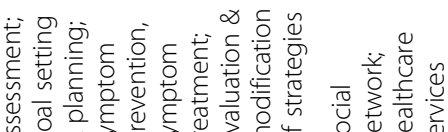
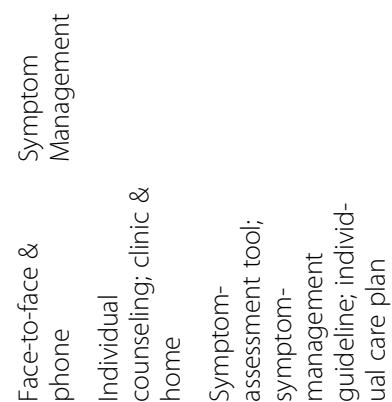

这

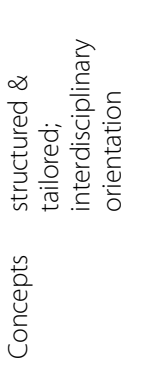

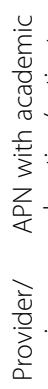

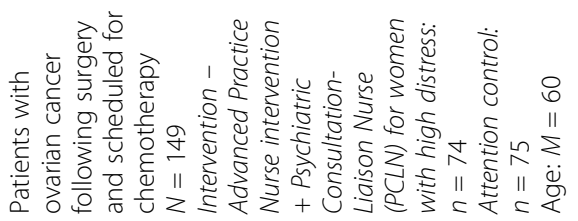

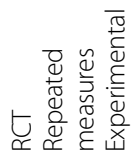

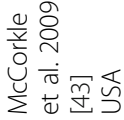

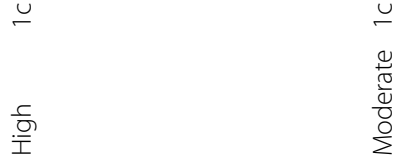

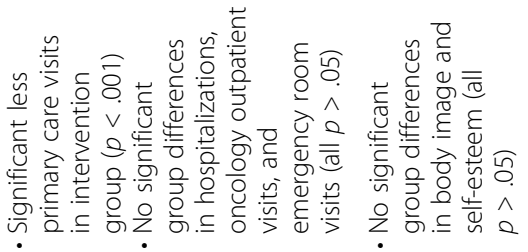

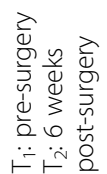

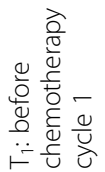

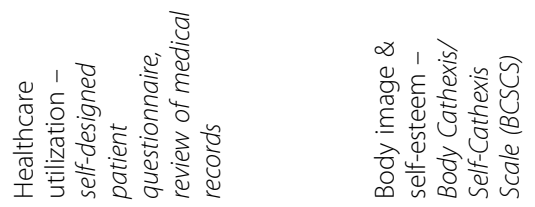

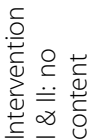

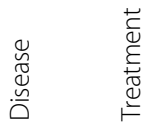

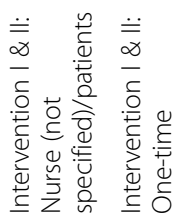

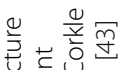

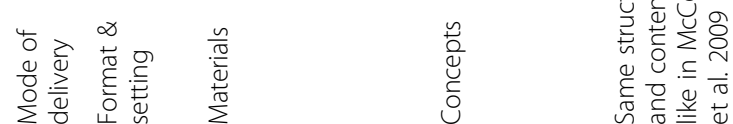

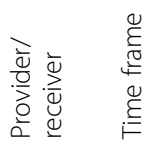

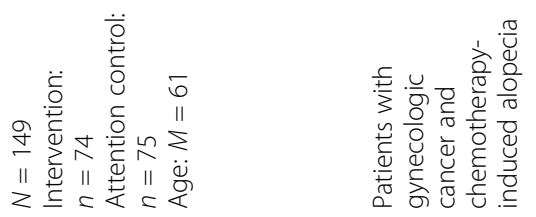

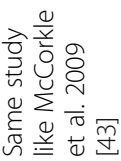

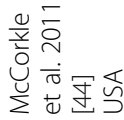

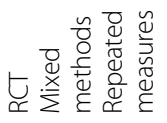

宁

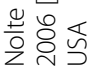




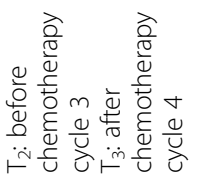

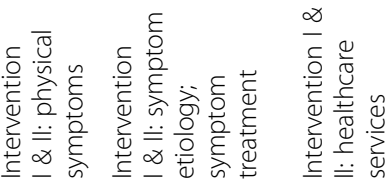

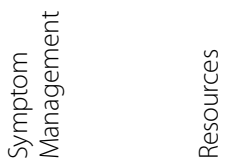

y

$\frac{\pi}{\frac{\pi}{\pi}}$
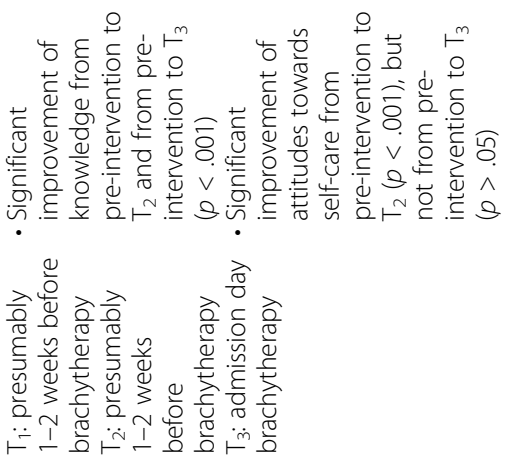

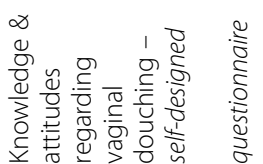

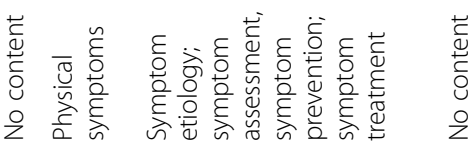

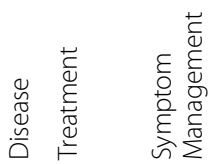

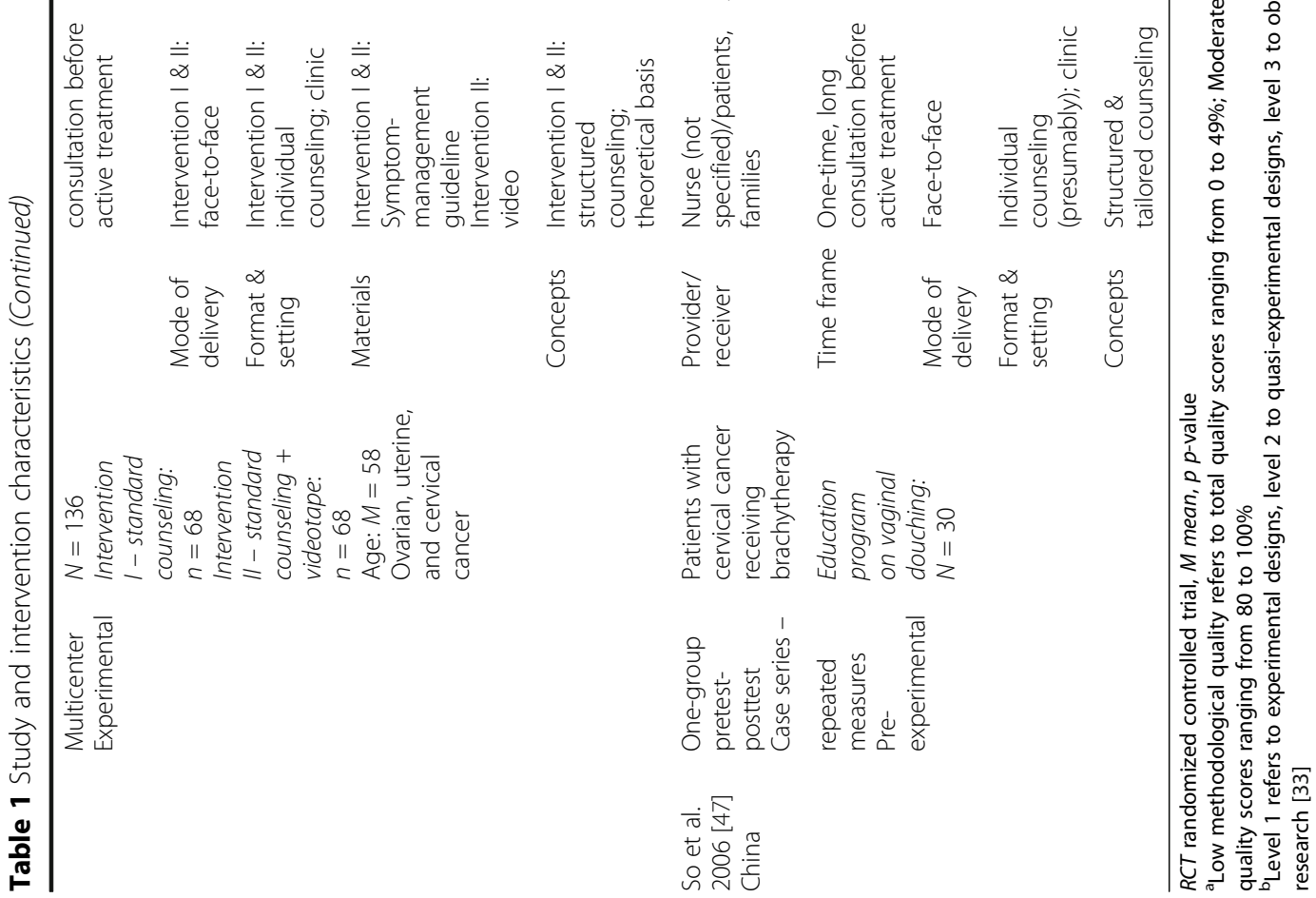


two interventions against one another [48]. Thereby, counseling by a head nurse plus the provision of written information reduced urinary tract infection not significantly more than counseling by a staff nurse [48].

Psychosocial symptoms and issues were examined in seven research projects. In experimental investigations, no significant effects on anxiety [42], depression [42, 43], sexual functioning [26, 42], social support [42], overall uncertainty, and the uncertainty subscales of 'complexity' and 'ambiguity' [42] were found. Only the study that examined depression [43] was of high quality, whereas all others were of moderate methodological quality $[26,42]$. In contrast, sexual satisfaction [41] and the uncertainty subscale of 'inconsistency' [42] improved significantly with nurse counseling. However, none of these results are based on studies with high methodological quality. Contradictory results appeared in the uncertainty subscale of 'ambiguity'. One high-quality study observed positive effects on this outcome [43], whereas another moderate-quality study did not [42]. In another moderate-quality study counseling plus a video tape improved body image and self-esteem not significantly more than standard counseling [45]. When considering pre-experimental investigations, positive effects appeared in attitude and knowledge regarding vaginal douching [47]. Moreover, knowledge about urinary catheter care improved significantly with counseling by a head nurse plus written information when compared with counseling by a staff nurse [48]. However, both studies are of low quality.

Moreover, two experimental studies with high methodological quality demonstrated positive effects of counseling on symptom distress $[25,43]$. One of these studies additionally investigated symptom severity, symptom consequences, and symptom controllability [25], although only symptom severity improved significantly with nurse counseling. The results of these studies relate to physical and psychosocial symptoms, but are not distinguishable on this level.

\section{Self-care performance}

In the moderate-quality pre-experimental study by Liu et al. [48], counseling by a head nurse plus the provision of written information improved urinary self-care performance not significantly more than counseling by a staff nurse.

\section{Healthcare utilization}

In one experimental study [44] investigating healthcare utilization nurse counseling yielded significantly fewer primary care visits, but no significant group differences in the number of hospitalizations, oncology outpatient visits, or emergency room visits.

\section{Structural components of nurse counseling}

In total, eight main components with various subcomponents characterizing the structure of nurse counseling in gynecologic oncology were identified (see Table 2 that includes a definition for each coded component).

\section{Provider and receiver}

Of the studies reporting sufficient details, two interventions were provided by a non-Advanced Practice Nurse (APN) without academic education [48], two interventions were by a non-APN with academic education [25, 42], and three interventions were implemented by an APN with academic education [26, 43, 44, 46]. Three interventions were offered to women's families in addition to the women themselves [26, 43, 44, 47].

\section{Time frame}

The time points of intervention delivery ranged from the time before, during, and after active treatment. Two interventions were offered as one-time consultations $[45,47]$ and eight as repeated consultations [25, 26, 41-44, 46, 48]. Of the studies reporting information about the duration of each counseling session, one intervention can be characterized as short consultation [46] and two interventions as long consultations [42, 47].

\section{Mode of delivery, format, and setting}

Seven interventions were delivered face-to-face [26, 41, $45,47,48]$, one was delivered by phone [46], and one was delivered by internet [25]. In two interventions, face-to-face counseling was combined with counseling by phone [42-44]. Ten interventions employed an individual format for counseling [25, 26, 41, 43-48], and one combined individual counseling with group counseling [42]. Six interventions were offered in a clinical setting [42, 45, 47, 48], and three interventions were provided additionally at home $[26,41,43,44]$.

\section{Materials}

Symptom-assessment tools [25, 43, 44, 46] were used in three interventions, symptom-management guidelines in six $[25,41,43-46]$, individual care plans in three [25, 41, $43,44]$, leaflets in four [26, 46-48], and videos in two interventions $[45,47]$.

\section{Concepts}

Seven interventions were structured and tailored $[25,26,41-44,46,47]$, and four interventions were structured only $[45,48]$. Furthermore, four interventions had an interdisciplinary orientation towards solving patients' problems $[25,26,43,44,46]$, whereas an explicit theoretical basis was described for five interventions (e.g., Orem's Self-Care Theory) [25, 42-45]. 
Table 2 Structure and content components of nurse counseling in gynecologic oncology

\begin{tabular}{|c|c|c|c|}
\hline $\begin{array}{l}\text { Structural main } \\
\text { components }\end{array}$ & Structural sub-components & $\begin{array}{l}\text { Studies containing } \\
\text { each coded component }\end{array}$ & $\begin{array}{l}\text { Components with the } \\
\text { best available evidence }\end{array}$ \\
\hline \multirow[t]{3}{*}{ Provider $^{a}$} & Non-APN without academic education & [48] & \\
\hline & Non-APN with academic education & {$[25,42]$} & $\checkmark$ \\
\hline & APN with academic education & {$[26,43,44,46]$} & $\checkmark$ \\
\hline \multirow[t]{2}{*}{ Receiver $^{\mathrm{b}}$} & Patients & {$[25,26,41-48]$} & $\checkmark$ \\
\hline & Families & {$[26,43,44,47]$} & $\checkmark$ \\
\hline \multirow[t]{9}{*}{ Time frame $^{c}$} & Before active treatment & {$[45,47]$} & \\
\hline & During active treatment & [48] & \\
\hline & After active treatment & [46] & \\
\hline & During and after active treatment & {$[43,44]$} & $\checkmark$ \\
\hline & $\begin{array}{l}\text { Before, during, and after active } \\
\text { treatment }\end{array}$ & {$[25,26,41,42]$} & $\checkmark$ \\
\hline & One-time consultation & {$[45,47]$} & \\
\hline & Repeated consultation & {$[25,26,41-44,46,48]$} & \\
\hline & Short consultation & {$[46]$} & \\
\hline & Long consultation & {$[42,47]$} & \\
\hline \multirow[t]{4}{*}{ Mode of delivery ${ }^{d}$} & Face-to-face & {$[26,41,45,47,48]$} & \\
\hline & Phone & {$[46]$} & \\
\hline & Internet & [25] & $\checkmark$ \\
\hline & Face-to-face and phone & [42-44] & $\checkmark$ \\
\hline \multirow[t]{2}{*}{ Format $^{e}$} & Individual counseling & {$[25,26,41,43-48]$} & $\checkmark$ \\
\hline & Individual and group counseling & {$[42]$} & \\
\hline \multirow[t]{2}{*}{ Setting $^{f}$} & Clinic & {$[42,45,47,48]$} & \\
\hline & Clinic and home & {$[26,41,43,44]$} & $\checkmark$ \\
\hline \multirow[t]{5}{*}{ Materials } & Symptom-assessment tools ${ }^{9}$ & {$[25,43,44,46]$} & \\
\hline & Symptom-management guidelines ${ }^{h}$ & {$[25,41,43-46]$} & \\
\hline & Individual care plans ${ }^{i}$ & {$[25,41,43,44]$} & \\
\hline & Leaflets $^{j}$ & {$[26,46-48]$} & \\
\hline & $V_{\text {Videos }}{ }^{k}$ & {$[45,47]$} & \\
\hline \multirow[t]{4}{*}{ Concepts } & Structured counseling' & {$[45,48]$} & \\
\hline & Structured and tailored counseling ${ }^{\mathrm{m}}$ & {$[25,26,41-44,46,47]$} & $\checkmark$ \\
\hline & Interdisciplinary orientation ${ }^{n}$ & {$[25,26,43,44,46]$} & \\
\hline & Theoretical basis $^{\circ}$ & {$[25,42-45]$} & \\
\hline $\begin{array}{l}\text { Content main } \\
\text { components }\end{array}$ & Content sub-components & Studies containing each coded component & $\begin{array}{l}\text { Components with the } \\
\text { best available evidence }\end{array}$ \\
\hline \multirow[t]{4}{*}{ Disease } & Etiology $y^{p}$ & {$[42,46]$} & \\
\hline & Diagnostic procedures ${ }^{q}$ & [46] & \\
\hline & Physical symptoms ${ }^{r}$ & {$[25,42-44,46]$} & $\checkmark$ \\
\hline & Psychosocial symptoms ${ }^{5}$ & {$[25,41-44,46]$} & $\checkmark$ \\
\hline \multirow[t]{4}{*}{ Treatment } & Therapeutic procedures ${ }^{t}$ & {$[26,42]$} & \\
\hline & Decision-making ${ }^{\mathrm{u}}$ & {$[43,44]$} & $\checkmark$ \\
\hline & Physical symptoms ${ }^{\vee}$ & {$[25,42-48]$} & $\checkmark$ \\
\hline & Psychosocial symptoms ${ }^{w}$ & {$[25,26,41-44,46]$} & $\checkmark$ \\
\hline \multirow[t]{2}{*}{ Symptom-management ${ }^{x}$} & Symptom etiology & {$[25,26,41,43-47]$} & $\checkmark$ \\
\hline & Symptom assessment & {$[25,43,44,47,48]$} & $\checkmark$ \\
\hline
\end{tabular}


Table 2 Structure and content components of nurse counseling in gynecologic oncology (Continued)

\begin{tabular}{llll}
\hline & Goal-setting and planning & {$[25,43,44]$} & $\checkmark$ \\
& Symptom prevention & {$[25,26,41-44,47,48]$} & $\checkmark$ \\
& Symptom treatment & {$[25,26,41-48]$} & $\checkmark$ \\
& Evaluation and modification of & {$[25,43,44,48]$} & $\checkmark$ \\
symptom management strategies & & $\checkmark$ \\
Resources $^{y}$ & Personal capabilities & {$[25,26,42,46]$} & $\checkmark$ \\
\hline
\end{tabular}

${ }^{a}$ The intervention provider, including specifications and educational background

${ }^{b}$ Patients and families (partners, parents etc.) as intervention receivers

'The time points (before/during/after active treatment), frequency (one-time/repeated counseling), and duration of each counseling session (sessions up to 20 min were considered as short consultations and sessions exceeding these frames as long consultations)

${ }^{\mathrm{d}}$ The interaction channel by which interventions are delivered to recipients

e Individual counseling is provided to patients and families, whereas group counseling is delivered to a group of patients

'The counseling location, including inpatient and outpatient clinics and patients' homes

${ }^{g}$ Any tools utilized by nurses or patients for symptom assessment

${ }^{\mathrm{h}}$ Standardized recommendations regarding symptom self-care

'Any nursing plans regarding the care of individual patients

${ }^{\mathrm{j} B o o k l e t s}$ by official organizations (such as Cancer Aid) and information sheets prepared by healthcare providers

kVideotapes shown or given to patients

'The intervention is delivered the same way for all recipients

mThe intervention is adapted to the individual needs, priorities, and meanings of recipients

${ }^{n}$ Counselors consider interdisciplinary requirements to solve patients' problems, such as collaborative and coordinative activities

${ }^{\circ}$ Any theoretical foundation of the counseling program (e.g., Orem's self-care theory)

${ }^{\mathrm{P} C a u s e s}$ of gynecological neoplasia

${ }^{\mathrm{q}}$ Any procedures used to diagnose gynecological neoplasia, including a discussion of diagnostic results

'Disease-related physical symptoms

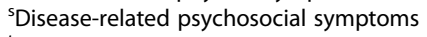

${ }^{t}$ Any medical therapy for gynecological neoplasia, such as surgery, chemotherapy, or radiotherapy

'Patients' decisions affecting subsequent treatment

v'Treatment-related physical symptoms

wTreatment-related psychosocial symptoms

${ }^{x}$ The management of disease and treatment-related symptoms, including their causes, their assessment, goal-setting and subsequent planning of management strategies, prevention and treatment, as well as evaluation and modification of management strategies

${ }^{y}$ Any resources of patients to cope with disease and treatment-related issues, including personal capabilities (such as personal strengths, financial resources), the social network (utilization and communication), and healthcare services (utilization and communication)

Structural components associated with significant improvements of outcomes in the studies with the best available evidence $[25,43,44]$ included counseling by a nurse with an academic education providing repeated, individual consultations during and after active treatment in a structured, tailored, interdisciplinary orientated, and theoretically based manner. Furthermore symptom assessment tools, symptom-management guidelines, and/or individual care plans were utilized in these interventions. The components face-to-face counseling combined with phone counseling [43, 44], internet counseling [25], counseling of women's families [43, $44]$, consultations in the clinic combined with consultations at home [43, 44], and counseling before active treatment [25] were each time applied in just one of the interventions with the most trustworthy results. Consequently, the presence as well as the absence of these components was associated with specific benefits. All other components were primarily associated with non-significant improvements when taking into account for each component the best available evidence (Additional file 5).

\section{Content components of nurse counseling}

Data synthesis yielded four main components with different sub-components representing the themes discussed during nurse counseling (Table 2).

\section{Disease and treatment}

Counseling on issues pertinent to disease or treatment focused on disease etiology in two interventions $[42,46]$, on diagnostic or treatment-related procedures in three interventions $[26,42,46]$, and on treatment-related decisionmaking in one intervention [43, 44]. Physical symptoms were addressed in nine [25, 42-48] and psychosocial symptoms in six interventions $[25,26,41-44,46]$.

\section{Symptom management}

Eight interventions focused on symptom etiology [25, 26, $41,43-47]$, five on symptom-assessment [25, 43, 44, 47, $48]$, two on goal setting and planning [25, 43, 44], 11 on symptom prevention and/or treatment [25, 26, 41-48], and four on evaluation and modification of symptommanagement strategies $[25,43,44,48]$. 


\section{Resources}

How to utilize personal capabilities as resources to cope with disease and treatment-related issues was discussed in four interventions [25, 26, 42, 46]. Utilization of the social network was addressed in five [26, 41-44, 46] and utilization of healthcare services in seven interventions [25, 26, 42-46].

Content components intertwined with significant improvements of outcomes in the studies providing the best available evidence [25, 43, 44], included comprehensive counseling on the management of disease and treatmentrelated physical and psychosocial symptoms (from symptom etiology and symptom-assessment to the evaluation and modification of symptom-management strategies), as well as advice on the utilization of healthcare services. However, both the inclusion and exclusion of issues related to treatment-related decision-making [43, 44], utilization of personal capabilities [25], and utilization of the social network $[43,44]$ were associated with significant positive effects in these studies. All other components were primarily associated with non-significant improvements when taking into account for each component the best available evidence (Additional file 5).

\section{Discussion}

This systematic review included ten studies, which tested 11 interventions in total. The results are limited to women with gynecologic cancer since none of the studies investigated women with pre-cancer confirmed by colposcopy/biopsy. One reason for this could be that focusing solely on rigorously confirmed conditions may complicate recruitment and result in smaller samples, as researchers need to review the diagnostic findings of potential participants. More than half of the studies represent pre-experimental investigations, studies with low methodological quality and/or pilot studies with small samples [25, 26, 42, 46-48]. Thus, when considering level of evidence, methodological quality, and replicated findings, the most robust results indicate that nurse counseling can improve symptom distress [25, 43], but not depression $[42,43]$. These results are replicated in at least one experimental study with high quality. Moreover, eight structural components and four content components of nurse counseling with different subcomponents were identified and examined on their association with positive effects.

\section{Effects of nurse counseling}

The quality of life results show less unequivocal evidence of good quality. The results that were replicated across studies (e.g., functional quality of life) are supported by weak evidence $[26,42,46]$ and those with stronger evidence (e.g., overall quality of life) [43] are contradictory $[26,42]$. The contradictory findings may be due to different quality of life measures used across studies. Some measures inquired about symptom occurrence (e.g., [26]), whereas others focused on the impact of symptoms on quality of life (e.g., [43]). Additionally, overall quality of life is based on single items in some measures (e.g., [26]) and on total scores in others (e.g., [42]). Another issue is that many study reports do not describe how an intervention may yield intended quality of life effects. Thus, few studies may have selected the most proximal measures of cause-effect relations. However, other studies of breast cancer patients also observed inconsistent effects of nurse counseling on quality of life [49-51].

One study [48] showed that physical symptoms do not improve with counseling plus an add-on (leaflet, nurses' position) when compared to standard counseling. Although this result is lacking strong evidence, it is reasonable that other factors contribute to the benefits of counseling. For example, previous research showed rather unfavorable results for the provision of written information alone [52]. The same applies to self-care performance, which also did not improve with counseling plus an add-on [48]. Overall, it is remarkable that only one study measured physical symptoms, although many interventions focused on their management [42, 43, 45-48]. It is possible that these studies evaluated them within quality of life $[42,43,46]$ and symptom severity [25] measures. For psychosocial issues, it is hardly possible to draw any firm conclusions since the evidence for them is almost always weak. Most robust results indicate that nurse counseling cannot improve depression $[42,43]$. This may be because that depression is a state or a personality trait [53]. A non-psychotherapeutic intervention such as nurse counseling should primarily improve depression as a state. The measures of included studies [42, 43] do not make this distinction, and thus, possibly failed to show depression state changes. However, in other studies with breast cancer patients, depression also remained unchanged with nurse counseling [49, 50, 54]. The reported improvements of symptom severity and distress [25, 43], which relate to physical and psychosocial symptoms and rely on strong evidence, indicate that nurse counseling has the potential to impact biopsychosocial symptoms. Particularly regarding symptom distress, two studies, one that employed an APN intervention [43] and one that tested a web-based intervention [25], came to the same result. This promising result was also found in previous nursing research with breast cancer patients [55].

In addition, nurse counseling seems to have few effects on healthcare utilization [44]. McCorkle et al. [44] argue that their APN intervention reduced primary care visits because it addressed women's everyday concerns, whereas emergency room visits remained unchanged because patients were encouraged to seek urgent care if necessary. Conversely, hospitalizations and oncology 
outpatient visits were scheduled follow-ups, which in cancer care rely on well-established, pre-defined protocols and were thus not preventable. In contrast, previous research showed reduced emergency room and hospital visits due to oncology nursing [56].

\section{Structural components of nurse counseling}

At least two-thirds of the interventions were implemented repeatedly [25, 26, 41-46, 48], face-to-face [26, 41-45, 47, $48]$, in an individual format [25, 26, 41, 43-48], in the clinical setting $[25,26,41-48]$ with timely proximity to active treatment $[25,26,41-45,47,48]$ and thereby involved structured and tailored counseling [25, 26, 41-44, 46, 47]. These components were also very common in previous work $[27,57]$ and are probably seen as part of a feasible, sustainable intervention structure. Around active treatment, patients have many clinical appointments, illnessrelated concerns, and self-care needs [19, 20, 22]. Their situation is mostly too complex and fluctuates too much for one consultation, and in the clinic, nurses can address patients' questions after physician appointments. Of these rather frequently used components, repeated, individual consultations offered during and after active treatment, and delivered as both structured and tailored interventions, yielded the most robust improvements $[25,43,44]$.

In contrast, few interventions involved home [26, 41, 43, 44], group [42], phone [42-44, 46], or internet [25] counseling, additional family members [26, 43, 44, 47], or symptom assessment tools. The common absence of symptom assessment tools is noteworthy, since many interventions focused on symptom management [25, 26, 41-48]. However, many of these components (e.g., phone counseling) can bridge critical transitions (e.g., discharge), between the clinical and home settings, but some might be difficult to implement (e.g., home counseling). Remarkably, these components were most often present in interventions with academically educated nurses [25, 26, 42-44, 46], who are probably more familiar with sophisticated, innovative approaches and roles. In this context, it must be emphasized that this provider specification, as well as the utilization of symptom assessment tools [25, 43, 44], were among those components that were associated with the most trustworthy effects.

\section{Content components of nurse counseling}

Most frequently, counseling addressed treatmentrelated physical symptoms [25, 42-48], symptom etiology [25, 26, 41, 43-47], symptom prevention and/or treatment $[25,26,41-48]$, and utilization of healthcare services [25, 26, 42-46]. Nurses and patients may see these themes as being at the core of nursing practice and competence. Moreover, many interventions were carried out around the time of active treatment $[25,26,41-45,47,48]$, during which questions, such as what physical symptoms should be expected, and how they develop, how they are preventable and treatable, may have been more prominent than other themes. All these frequently used components were associated with significant effects in the studies providing the best available evidence [25, 43, 44].

In few interventions, counseling included disease etiology $[42,46]$, diagnostic or treatment-related procedures [26, 42, 46], treatment-related decision-making [43, 44], as well as goal setting and planning within symptom management $[25,43,44]$. Interestingly these themes were only discussed in interventions with academically educated nurses. We assume that disease and treatment-related issues (e.g., diagnostics) were not addressed in other interventions because they are traditionally more assigned to physicians' competence. In particular, health-related decision-making can be an important theme when patients are in a dilemma to help them determine which options represent the most satisfying outcome for them [58]. However, in the most trustworthy studies, symptom-management was addressed comprehensively [25, 43, 44], whereas both the inclusion [43, 44] and exclusion [25] of health-related decision-making was associated with positive effects.

\section{Limitations}

The results of this systematic review are limited to women with gynecologic cancer and our restrictive definition of pre-cancer excluded studies concerning less rigorously confirmed conditions. On the one hand, it was critical to draw the line at colposcopy/biopsy-confirmed conditions, and on the other hand, it was not reasonable to exclude women with pre-cancer from the research interest of this review since they need to be considered in gynecologic oncology. Furthermore, a broad concept of counseling was adopted. Thus, included interventions can also be characterized as psychosocial or supportive programs. Additionally, preexperimental studies were eligible, even though these generally exhibit less internal validity than experimental investigations. The additional objective of identifying counseling components justified the sourcing of all available intervention studies using quantitative designs. Moreover, it was not feasible to reconstruct which effects on symptoms were observed in quality of life measures since studies did not report findings of single items. Partially limited study reporting also restricted the data synthesis regarding the structure and content of nurse counseling.

\section{Conclusions}

The current evidence base about the effectiveness of nurse counseling appears to be too fragmented and inconsistent to establish comprehensive implications for 
practice. Nevertheless, the results suggest that nurse counseling ameliorates symptom distress. For women exhibiting depressive symptoms, referral to appropriate psychological services is recommended. Patient outcomes may be improved by nurse counselors with an academic education administering repeated consultations in an individual format during and after active treatment by including structured, tailored, interdisciplinary orientated, and theoretically based counseling concepts, as well as specific materials, a comprehensive management of disease and treatment-related symptoms and the utilization of healthcare services. More welldesigned, large-scale studies including women with confirmed pre-cancer, based on a theoretical model of the intervention effect thereafter translated in the selection of outcome measures, are required. Moreover, combined and innovative counseling forms involving the social environment, various tools and materials, issues touching on physicians' competence, and specific symptom management strategies remain an issue for future studies. In particular, the identified components can be used in future studies as well as by healthcare providers for the systematic development of nurse counseling as a complex intervention. Therefore, it must be carefully determined how to combine and adopt various components for specific patient groups.

\section{Additional files}

Additional file 1: Critical appraisal tools. Description of data: Standardized Critical Appraisal Checklist from the JBI. (DOCX $18 \mathrm{~kb}$ )

Additional file 2: Levels of evidence for effectiveness. Description of data: JBI levels of evidence. (DOCX $14 \mathrm{~kb}$ )

Additional file 3: Critical appraisal of included studies. Description of data: Critical appraisal of included experimental and pre-experimental studies. (DOCX $43 \mathrm{~kb}$ )

Additional file 4: Outcomes listed by intervention effects. Description of data: A table listing all identified outcomes by significant and non-significant improvements due to the tested interventions.) (DOCX $67 \mathrm{~kb}$ )

Additional file 5: Structure and content components associated with significant and non-significant effects. Description of data: A table listing all components by their effects on all measured outcomes within included studies. (DOCX $565 \mathrm{~kb})$

\section{Abbreviations}

APN: Advanced practice nurse; JBI: Joanna Briggs Institute; MAStARI: Meta analysis of statistics assessment and review instrument; MeSH: Medical subject heading

\section{Acknowledgements}

None.

\section{Funding}

This research did not receive any specific funding from agencies in the public, commercial, or not-for-profit sectors.

\section{Availability of data and materials}

SPSS ${ }^{\oplus}$ files and Atlas.ti ${ }^{\oplus}$ files are available from the first author upon reasonable request. All other datasets supporting the conclusions of this article are included within the article and its additional files.

\section{Authors' contributions}

SR conceptualized the study and performed the literature search. SR and AK conducted the study selection of all retrieved records by the inclusion and exclusion criteria. SR and AK assessed the methodological quality of all included studies. SR performed the data synthesis. AK, HM, and BS reviewed the data synthesis. SR drafted the manuscript. AK, HM, and BS revised the manuscript. All authors read and approved the final manuscript.

\section{Authors' information}

This systematic review is part of the PhD project of SR, supervised by HM and SB.

\section{Ethics approval and consent to participate}

Not applicable.

\section{Consent for publication}

Not applicable.

\section{Competing interests}

The authors declare that they have no competing interest.

\section{Publisher's Note}

Springer Nature remains neutral with regard to jurisdictional claims in published maps and institutional affiliations.

\section{Author details}

'Department of Nursing Science, University of Vienna, Alser Strasse 23, 1080 Vienna, Austria. ${ }^{2}$ Institute for Applied Nursing Sciences IPW-FHS, University of Applied Sciences FHS St. Gallen, Rosenbergstrasse 59, 9001 St. Gallen, Switzerland. ${ }^{3}$ Sydney Nursing School, The University of Sydney, Mallett Street 88, Camperdown, NSW 2050, Australia.

Received: 31 March 2017 Accepted: 31 July 2017

Published online: 03 August 2017

References

1. Gunderson CC, Nugent EK, Elfrink SH, Gold MA, Moore KN. A contemporary analysis of epidemiology and management of vaginal intraepithelial neoplasia. Am J Obstet Gynecol. 2013; doi:10.1016/j.ajog.2013.01.047.

2. Joura EA, Lösch A, Haider-Angeler MG, Breitenecker G, Leodolter S. Trends in vulvar neoplasia. Increasing incidence of vulvar intraepithelial neoplasia and squamous cell carcinoma of the vulva in young women. J Reprod Med. 2000;45:613-5.

3. Santesso N, Mustafa RA, Schunemann HJ, Arbyn M, Blumenthal PD, Cain J, Chirenje M, Denny L, De Vuyst H, Eckert LO, Forhan SE, Franco EL, Gage JC, Garcia F, Herrero R, Jeronimo J, Lu ER, Luciani S, Quek SC, Sankaranarayanan $R$, Tsu V, Broutet N. World Health Organization guidelines for treatment of cervical intraepithelial neoplasia 2-3 and screen-and-treat strategies to prevent cervical cancer. Int J Gynaecol Obstet. 2016; doi:10.1016/j.jigo.2015. 07.038

4. Sankaranarayanan R, Ferlay J. Worldwide burden of gynaecological cancer: the size of the problem. Best Pract Res Clin Obstet Gynaecol. 2006; doi:10.1016/j.bpobgyn.2005.10.007

5. Liebrich C, Brummer O, Von Wasielewski R, Wegener G, Meijer C, Iftner T, Petry KU. Primary cervical cancer truly negative for high-risk human papillomavirus is a rare but distinct entity that can affect virgins and young adolescents. Eur J Gynaecol Oncol. 2009;30:45-8.

6. Viens $\sqcup$, Henley SJ, Watson M, Markowitz LE, Thomas CC, Thompson TD, Razzaghi H, Saraiya M. Human Papillomavirus-associated cancers - United States, 2008-2012. Morb Mortal Wkly Rep. 2016; doi:10.15585/mmwr. mm6526a1.

7. Edey K, Murdoch J. FIGO staging in vulval and endometrial cancer. Obstet Gynaecol. 2010; doi:10.1576/toag.12.4.245.27616.

8. FIGO Committee. On gynecologic oncology. Current FIGO staging for cancer of the vagina, fallopian tube, ovary, and gestational trophoblastic neoplasia. Int J Gynaecol Obstet. 2009;105:3-4.

9. Massad LS, Einstein MH, Huh WK, Katki HA, Kinney WK, Schiffman M, Solomon D, Wentzensen N, Lawson HW. 2012 updated consensus guidelines for the management of abnormal cervical cancer screening tests and cancer precursors. Obstet Gynecol. 2013; doi:10.1097/AOG.0b013e3182883a34. 
10. German Society for Gynecology and Obstetrics (DGGG). Interdisziplinäre S2k-Leitlinie: Diagnostik, Therapie und Nachsorge des Vulvakarzinoms und seiner Vorstufen. 2015. http://www.awmf.org/uploads/tx_szleitlinien/015059k_S2k_Vulvakarzinom_und_Vorstufen_Diagnostik_Therapie_2016-11.pdf . Accessed 30 May 2016.

11. Suh DH, Lee KH, Kim K, Kang S, Kim JW. Major clinical research advances in gynecologic cancer in 2014. J Gynecol Oncol. 2015; doi:10.3802/jgo.2015.26. 2.156 .

12. Casey C, Chen LM, Rabow MW. Symptom management in gynecologic malignancies. Expert Rev Anticancer Ther. 2011; doi:10.1586/era.11.83.

13. Pirotta M, Ung L, Stein A, Conway EL, Mast TC, Fairley CK, Garland S. The psychosocial burden of human papillomavirus related disease and screening interventions. Sex Transm Infect. 2009; doi:10.1136/sti.2009.037028.

14. Senn B, Eicher M, Mueller MD, Hornung R, Fink D, Baessler K, Hampl M, Denhaerynck K, Spirig R, Engberg S. A patient-reported outcome measure to identify occurrence and distress of post-surgery symptoms of WOMen with vulvAr Neoplasia (WOMAN-PRO) - a cross sectional study. Gynecol Oncol. 2013; doi:10.1016/j.ygyno.2012.12.038.

15. Dodd M, Janson S, Facione N, Faucett J, Froelicher ES, Humphreys J, Lee K, Miaskowski C, Puntillo K, Rankin S, Taylor D. Advancing the science of symptom management. J Adv Nurs. 2001;33:668-76.

16. Ratner ES, Foran KA, Schwartz PE, Minkin MJ. Sexuality and intimacy after gynecological cancer. Maturitas. 2010; doi:10.1016/j.maturitas.2010.01.015

17. Nagele E, Reich O, Greimel E, Dorfer M, Haas J, Trutnovsky G. Sexual activity, psychosexual distress, and fear of progression in women with human Papillomavirus-related premalignant genital lesions. J Sex Med. 2016; doi:10. 1016/j.jsxm.2015.12.012.

18. Cendejas BR, Smith-McCune KK, Khan MJ. Does treatment for cervical and vulvar dysplasia impact women's sexual health? Am J Obstet Gynecol. 2015: doi:10.1016/j.ajog.2014.05.039.

19. Sandsund C, Pattison N, Doyle N, Shaw C. Finding a new normal: a grounded theory study of rehabilitation after treatment for upper gastrointestinal or gynaecological cancers - the patient's perspective. Eur J Cancer Care (Engl). 2013; doi:10.1111/ecc.12016.

20. Senn B, Gafner D, Happ MB, Eicher M, Mueller MD, Engberg S, Spirig R. The unspoken disease: symptom experience in women with vulval neoplasia and surgical treatment: a qualitative study. Eur J Cancer Care (Engl). 2011; doi:10.1111/j.1365-2354.2011.01267.x.

21. Oshima S, Kisa K, Terashita T, Habara M, Kawabata H, Maezawa M. A qualitative study of Japanese patients' perspectives on post-treatment care for gynecological cancer. Asian Pac J Cancer Prev. 2011;12:2255-61.

22. Schulman-Green D, Bradley EH, Nicholson NR Jr, George E, Indeck A McCorkle R. One step at a time: self-management and transitions among women with ovarian cancer. Oncol Nurs Forum. 2012; doi:10.1188/12.onf. 354-360.

23. Galaal KA, Deane K, Sangal S, Lopes AD. Interventions for reducing anxiety in women undergoing colposcopy. Cochrane Database Syst Rev. 2007; doi: 10.1002/14651858.CD006013.pub2.

24. Chan YM, Lee PW, Ng TY, Ngan HY. Could precolposcopy information and counseling reduce women's anxiety and improve knowledge and compliance to follow-up? Gynecol Oncol. 2004; doi:10.1016/j.ygyno.2004.07. 002.

25. Donovan HS, Ward SE, Sereika SM, Knapp JE, Sherwood PR, Bender CM, Edwards RP, Fields M, Ingel R. Web-based symptom management for women with recurrent ovarian cancer: a pilot randomized controlled trial of the WRITE symptoms intervention. J Pain Symptom Manag. 2014; doi:10.1016/j.jpainsymman.2013.04.005.

26. Maughan $\mathrm{K}$, Clarke $\mathrm{C}$. The effect of a clinical nurse specialist in gynaecological oncology on quality of life and sexuality. J Clin Nurs. 2001;10:221-9.

27. Cook O, Mclntyre M, Recoche K. Exploration of the role of specialist nurses in the care of women with gynaecological cancer: a systematic review. J Clin Nurs. 2014; doi:10.1111/jocn.12675.

28. Grant MJ, Booth A. A typology of reviews: an analysis of 14 review types and associated methodologies. Health Inf Libr J. 2009; doi:10.1111/j.14711842.2009.00848.x

29. Moher D, Liberati A, Tetzlaff J, Altman DG. Preferred reporting items for systematic reviews and meta-analyses: the PRISMA statement. Int I Surg 2010; doi:10.1016/j.ijsu.2010.02.007.

30. Joanna Briggs Institute. Joanna Briggs Institute Reviewers' Manual: 2014 edition. 2014. https://joannabriggs.org/assets/docs/sumari/ReviewersManual2014.pdf. Accessed 10 Jan 2015.
31. Dizon JM, Reyes JJ. A systematic review on the effectiveness of external ankle supports in the prevention of inversion ankle sprains among elite and recreational players. J Sci Med Sport. 2010; doi:10. 1016/j.jsams.2009.05.002

32. Luctkar-Flude M, Groll D. A systematic review of the safety and effect of Neurofeedback on fatigue and cognition. Integr Cancer Ther. 2015; doi:10. $1177 / 1534735415572886$

33. Joanna Briggs Institute. New JBI Levels of Evidence. 2013. https:// joannabriggs.org/assets/docs/approach/JBI-Levels-of-evidence_2014.pdf. Accessed 16 Feb 2016

34. Higgins JPT, Green S. Cochrane handbook for systematic reviews of interventions version 5.1.0. Chichester: Wiley-Blackwell; 2011.

35. Schreier M. Qualitative content analysis in practice. Los Angeles: SAGE Publications; 2012.

36. Schreier M. Ways of doing qualitative content analysis: disentangling terms and terminologies. Forum Qual Soc Res. 2014; doi:10.17169/fas-15.1.2043.

37. Koller A, Miaskowski C, De Geest S, Opitz O, Spichiger E. A systematic evaluation of content, structure, and efficacy of interventions to improve patients' self-management of cancer pain. J Pain Symptom Manag. 2012; doi:10.1016/j.jpainsymman.2011.08.015.

38. Greaves CJ, Sheppard KE, Abraham C, Hardeman W, Roden M, Evans PH Schwarz P. Systematic review of reviews of intervention components associated with increased effectiveness in dietary and physical activity interventions. BMC Public Health. 2011; doi:10.1186/1471-2458-11-119.

39. Ryan P, Lauver DR. The efficacy of tailored interventions. J Nurs Scholarsh. 2002;34:331-7.

40. Bryant-Lukosius D, Dicenso A, Browne G, Pinelli J. Advanced practice nursing roles: development, implementation and evaluation. J Adv Nurs. 2004; doi:10.1111/j.1365-2648.2004.03234.x.

41. Aktaş D, Terzioğlu F. Effect of home care service on the sexual satisfaction of patients with gynecologic cancer. Sex Disabil. 2014; doi:10.1007/s11195014-9370-8.

42. Chow KM, Chan CW, Chan JC, Choi KK, Siu KY. A feasibility study of a psychoeducational intervention program for gynecological cancer patients. Eur J Oncol Nurs. 2014; doi:10.1016/j.ejon.2014.03.011.

43. McCorkle R, Dowd M, Ercolano E, Schulman-Green D, Williams AL, Siefert $\mathrm{ML}$, Steiner J, Schwartz P. Effects of a nursing intervention on quality of life outcomes in post-surgical women with gynecological cancers. Psychooncology. 2009; doi:10.1002/pon.1365.

44. McCorkle R, Jeon S, Ercolano E, Schwartz P. Healthcare utilization in women after abdominal surgery for ovarian cancer. Nurs Res. 2011; doi:10.1097/NNR. ob013e3181ff77e4.

45. Nolte S, Donnelly J, Kelly S, Conley P, Cobb R. A randomized clinical trial of a videotape intervention for women with chemotherapy-induced alopecia: a gynecologic oncology group study. Oncol Nurs Forum. 2006; doi:10.1188/ 06.onf.305-311.

46. Cox A, Bull E, Cockle-Hearne J, Knibb W, Potter C, Faithfull S. Nurse led telephone follow up in ovarian cancer: a psychosocial perspective. Eur J Oncol Nurs. 2008; doi:10.1016/j.ejon.2008.06.002.

47. So WK, Yuen JK. Evaluation of an education programme for Chinese women receiving internal radiation for uterine cervical cancer. J Clin Nurs. 2006; doi: 10.1111/j.1365-2702.2006.01311.x.

48. Liu HE, Ya SF. The immediate and short-term effects of an educational program for post radical hysterectomy self-care of the lower urinary tract. Chang Gung Med J. 2001;24:440-5.

49. Cruickshank S, Kennedy C, Lockhart K, Dosser I, Dallas L. Specialist breast care nurses for supportive care of women with breast cancer. Cochrane Database Syst Rev. 2008; doi:10.1002/14651858.CD005634.pub2.

50. Arving C, Sjoden PO, Bergh J, Hellbom M, Johansson B, Glimelius B, Brandberg Y. Individual psychosocial support for breast cancer patients: a randomized study of nurse versus psychologist interventions and standard care. Cancer Nurs. 2007; doi:10.1097/01.ncc.0000270709.64790.05.

51. Kimman ML, Dirksen CD, Voogd AC, Falger $P$, Gijsen BC, Thuring M, Lenssen $A$, van der Ent F, Verkeyn J, Haekens C, Hupperets $P$, Nuytinck JK, van Riet $Y$, Brenninkmeijer SJ, Scheijmans $L$, Kessels A, Lambin P, Boersma LJ. Nurseled telephone follow-up and an educational group programme after breast cancer treatment: results of a $2 \times 2$ randomised controlled trial. Eur J Cancer. 2011; doi:10.1016/j.ejca.2010.12.003.

52. Hersch J, Juraskova I, Price M, Mullan B. Psychosocial interventions and quality of life in gynaecological cancer patients: a systematic review. Psychooncology. 2009; doi:10.1002/pon.1443. 
53. Clark LA, Vittengl J, Kraft D, Jarrett RB. Separate personality traits from states to predict depression. J Personal Disord. 2003;17:152-72.

54. Traeger L, McDonnell TM, McCarty CE, Greer JA, El-Jawahri A, Temel JS. Nursing intervention to enhance outpatient chemotherapy symptom management: patient-reported outcomes of a randomized controlled trial. Cancer. 2015; doi:10.1002/cncr.29585.

55. Heidrich SM, Brown RL, Egan JJ, Perez OA, Phelan CH, Yeom H, Ward SE. An individualized representational intervention to improve symptom management (IRIS) in older breast cancer survivors: three pilot studies. Oncol Nurs Forum. 2009; doi:10.1188/09.onf.e133-e143.

56. Kurtz ME, Kurtz JC, Given CW, Given B. Effects of a symptom control intervention on utilization of health care services among cancer patients. Med Sci Monit. 2006;12:Cr319-24.

57. Chow KM, Chan JC, Choi KK, Chan CW. A review of Psychoeducational interventions to improve sexual functioning, quality of life, and psychological outcomes in gynecological cancer patients. Cancer Nurs. 2015; doi:10.1097/ncc.0000000000000234.

58. Lorig KR, Holman H. Self-management education: history, definition, outcomes, and mechanisms. Ann Behav Med. 2003;26:1-7.

Submit your next manuscript to BioMed Central and we will help you at every step:

- We accept pre-submission inquiries

- Our selector tool helps you to find the most relevant journal

- We provide round the clock customer support

- Convenient online submission

- Thorough peer review

- Inclusion in PubMed and all major indexing services

- Maximum visibility for your research

Submit your manuscript at www.biomedcentral.com/submit
Biomed Central 